\title{
The NFKB1 polymorphism (rs4648068) is associated with the cell proliferation and motility in gastric cancer
}

Ying Chen ${ }^{1,2 \dagger}$, Renquan $\mathrm{Lu}^{1,2+}$, Hui Zheng ${ }^{1}$, Ran Xiao ${ }^{1}$, Jingjing Feng ${ }^{1}$, Hongling Wang ${ }^{2}$, Xiang Gao ${ }^{1}$ and Lin Guo $0^{1,2^{*}}$

\begin{abstract}
Background: We have demonstrated previously that NFKB1 single nucleotide polymorphism (SNP) rs4648068 GG homozygote was associated with the increased risk of gastric cancer in Chinese Han population. In this study, we constructed the recombinant plasmid pGL3-AA, pGL3-GG, pGL3-AA-NFKB and pGL3-GG-NFKB to investigate the function of rs4648068 by cell biology experiments.
\end{abstract}

Methods: Quantitative real-time PCR was used to detect NFKB1 SNP rs4648068 genotype in the patients with gastric cancer. Anti-NF-kB1 p50 polyclonal antibodies were used for immunohistochemical analysis of the tissue specimens. The subsection of NFKB1 containing the promoter site and adjacent three consecutive exons were obtained by PCR technique and subcloned into the vector pGL3-Basic. Dual-Luciferase reporter assay was used to detect the transcriptional activity of the constructed promoter. Effects of transcription factor NFKB1 on C/EBP $\beta$ expression were determined by chromatin immunoprecipitation and Western analysis. Furthermore, proliferation and invasion ability of the transduced cell were also measured and compared.

Results: Intensive staining for p50 expression was observed in the tissues of GG genotype patients, compared with those of GA group and AA genotype patients. The transcriptional activity of rs4648068 (A > G) by dual-Luciferase reporter assay suggested that the luciferase activity of homozygote group (pGL3-GG) was greater than that of the control (pGL3-AA), especially at the stimulation of LPS. We found that the luciferase activity was also influenced by pGL3-GG levels. The effects of NFKB1 rs4648068 were enhanced by rs4648065 on the transduced cells. The interaction between NFKB1 promoter nucleotide sequence and C/EBP $\beta$ was regulated by the functional SNP rs4648068 in SGC-7901 cells. Our data indicated that the transduction of pGL3 expression plasmid pGL3-GG-NFKB improved the proliferation and motility of gastric cancer cells. Correspondingly, the homozygote GG of SNP rs4648068 strengthened the transcriptional activity of NFKB1 and influenced the cell biological activity.

Conclusion: The transcriptional activity of NFKB1 was associated with SNP rs4648068, and this functional SNP site has the important effects on cell proliferation and motility.

Keywords: NFKB1, Polymorphism, Gastric cancer, Susceptibility, Single nucleotide polymorphism

\footnotetext{
* Correspondence: 1251487447@qq.com

${ }^{\dagger}$ Equal contributors

'Department of Clinical Laboratory, Shanghai Cancer Center, Fudan University, Shanghai 200032, China

${ }^{2}$ Department of Oncology, Shanghai Medical College, Fudan University, Shanghai 200032, China
}

\section{Biomed Central}

(c) 2015 Chen et al.; licensee BioMed Central. This is an Open Access article distributed under the terms of the Creative Commons Attribution License (http://creativecommons.org/licenses/by/4.0), which permits unrestricted use, distribution, and reproduction in any medium, provided the original work is properly credited. The Creative Commons Public Domain Dedication waiver (http://creativecommons.org/publicdomain/zero/1.0/) applies to the data made available in this article, unless otherwise stated. 


\section{Background}

Nuclear factor- $\mathrm{kB}(\mathrm{NF}-\mathrm{kB})$ regulates many cellular functions including cell proliferation, apoptosis, angiogenesis, immune response, cell adhesion and differentiation [1]. The signal pathway involved by NF-kB plays important roles in linking inflammation to tumor development and progression [2]. NF- $\mathrm{kB}$ family contains five members in mammals: NFKB1 encoding p50, NFKB2 encoding p52, RELA encoding p65, REL encoding c-Rel, and RELB encoding Rel-B. The most common dimer is the p65/p50 heterodimer, which is inhibited by IкB in the cytosol [3]. Internal gene mutations and external stimuli contribute to the release of activated NF- $\mathrm{kB}$ [4]. The elevated NF$\kappa \mathrm{B}$ levels have been reported to be associated with cancers [5-7].

Rs4648068 polymorphism locates at NFKB1 promoter region. Polymorphisms in the regulatory regions of the genes have been associated with variation in gene expression [8,9]. The rs4648068 polymorphism is hypothesized to have a significant effect on NF-kB1 expression and play a part in tumorigenicity.

In the previous case-control study, we have demonstrated the role of NFKB1 rs4648068 polymorphisms in gastric cancer susceptibility in Chinese Han population. The results further indicated that the subjects with the allelic homozygous GG in rs4648068 had an increased risk in gastric cancer group compared with that in controls $(P=0.005)[10]$. However, the motility-promoting function of this single nucleotide polymorphism (SNP) site in gastric cancer progression is still uncertain. To clarify the functional mechanisms of NFKB1 rs4648068 polymorphism, it is necessary to investigate the changes of NF-kB1 expression at cellular and molecular levels. Accordingly, the polymorphism rs4648068 might play a role in the development of gastric cancer.

In this study, we constructed the recombinant plasmids, containing the different SNP variants to investigate the changes on transcriptional activity of NFKB1. Additionally, the growth and invasion alteration of transduced cells was observed to further demonstrate the biological function of rs4648068 in gastric cancer.

\section{Methods}

\section{Patients' samples and cell lines}

In previous study, we conducted a large-scale casecontrol study on Chinese Han population to investigate the association of rs4648068 polymorphism with gastric cancer or clinic-pathologic variables of gastric cancer patients. To further verify its function, the expression levels were measured with 20 tissues from gastric cancer patients using immunohistochemical staining. Meanwhile, the genomic DNA of these patients was collected to do genotyping. The study design was approved by the Clinical Research Ethics Committee of the Fudan
University Shanghai Cancer Center. All of the participants signed informed consent documents prior to participating in this study. Paraffin-embedded gastric cancer tissue samples were collected from 20 patients with gastric cancer who were admitted to Fudan University Cancer Hospital (Shanghai, China) July 2014. All cases were gastric adenocarcinoma confirmed by pathologist. Only the patients whose clinical data (include diagnosis, age, sex, address, disease history, etc.) were intact were selected. The gastric carcinoma cell lines, SGC-7901 cells, MKN45 cells, HGC27 cells and the non-gastric cancer cell lines, $293 \mathrm{~T}$, Hela cells, were generous gifts from Laboratory of Oncology, Fudan University Shanghai Cancer Center, Shanghai.

\section{Sample preparation and NFKB1 genotyping}

Genomic DNA was extracted from peripheral blood samples of each study subject using the TIANamp Blood DNA Kit (Tiangen Biotech, China). NFKB1 SNPs rs4648068 were genotyped by SYBR allelic discrimination. The corresponding qRT-PCR specific primers pGL3-RTp1, pGL3-RTp2 and pGL3-RTp3 are listed in Table 1. PCRs were run in a $10 \mu \mathrm{L}$ reaction solution containing $30 \mathrm{ng}$ of template DNA, $5 \mu \mathrm{L}$ SYBR Premix Ex Taq (TAKARA, Japan) according to the manual. PCR was performed at $95^{\circ} \mathrm{C}$ for $10 \mathrm{~min}$ and 40 cycles at $95^{\circ} \mathrm{C}$ for $30 \mathrm{~s}$ and $58^{\circ} \mathrm{C}$ for $30 \mathrm{~s}$. The samples were amplified, read and analyzed in Option ${ }^{\circ}$ Fluorescence Temperature Cycler (MJ Research, Canada).

\section{Immunohistochemical staining}

Immunohistochemical staining was performed on $6-\mu \mathrm{m}$ sections from formalin-fixed, paraffin-embedded human tissues. The slides were deparaffinized and rehydrated ingraded ethanol solutions. Antigen retrieval was performed by heating the samples for $20 \mathrm{~min}$ in citrate buffer ( $\mathrm{pH}$ 6.0). The slides were then incubated with a rabbit anti-NF-kB p50 polyclonal antibody (1:100 dilution; ab7971, Abcam) overnight at $4^{\circ} \mathrm{C}$. Tissue sections were washed again in PBS and incubated with horseradish peroxidase-conjugated secondary antibodies for $60 \mathrm{~min}$ at $37^{\circ} \mathrm{C}$. Color was developed using diaminobenzidine as a chromogen and the slides were counterstained with hematoxylin.

\section{Evaluation of immunohistochemical staining results}

The NF-kB1 positive tissues were quantified based on the percentage of positive cells which were serially counted in one microscopic field. The cell counting was repeated in five random microscopic fields at $\times 400$ magnification. Two pathologists who were blinded to patient group independently interpreted the IHC staining results using positive index (PI). The positive index (PI) was calculated using the following formulation: $P I=i \times p$, where 
Table 1 Primers used in this study

\begin{tabular}{lll}
\hline Name & Sequence & Restriction enzyme \\
\hline pGL3-RTp1 & 5' TAA TTG TTA GAG ATT CCA A 3' & \\
pGL3-RTp2 & 5' TAA TTG TTA GAG ATT CCA G 3' & \\
pGL3-RTp3 & 5' ACA ATG TTA GAT TTT ACC ATG ATT 3' & Kpnl \\
pGL-promoterFor1 & 5'GGGGTACCGGTCATCCTAGATCGTACTAAG3' & Kpnl \\
pGL-promoterFor2 & 5'GGGGTACCATAAAAGAAGAGAGTGCTGGAG3' & Bgl|II \\
pGL-promoterRev & 5'GAAGATCTCCTTGACATATCATTTTAGTTG3' & BgIII \\
pGL-NFKBFor & 5'GAAGATCTATGACGCCCTTGCACTTGGCAGTGA3' \\
pGL-NFKBRev & 5'GAAAGCTTTAGCTGCTTTGAGAAGAGCT3' & HindIII \\
\hline
\end{tabular}

The restriction sites for primers are italics.

$i$ is intensity of staining ( 0 for negative, blue; 1 for weakly-positive, light yellow; 2 for medium positive, yellow; 3 for strong positive, brown), and $p$ is positive percentage of staining ( 1 for $\leqq 10 \%$; 2 for $11 \%-50 \%$; 3 for 51\%-75\%; 4 for $>75 \%$ ) [11]. Then, the positive index (PI) was calculated for each case. If there were divergences in the PI determined by the two pathologists, slides were rescored until a consensus was reached. Besides, differences in NF-kappaB1 expression between different groups were investigated using Kruskal-Wallis nonparametric test.

\section{The construction of recombinant plasmid}

The section containing NFKB1 promoter region with polymorphisms rs4648068 was obtained by PCR using primers pGL-promoterFor1 and pGL-promoterRev (Table 1). DNA templates were extracted from peripheral blood samples of gastric cancer patients using the method described above. The PCR products containing NFKB1 polymorphisms were digested by Bgl II and Kpn I and linked into the vector pGL3-basic (Promega, Madison, WI) to construct recombinant plasmid pGL3-AA and pGL3-GG. Meanwhile, pGL3-GG/TT containing rs4648065 site was established as above described method to investigate the co-effect on rs4648068. Furthermore, the sequence coding selected section of NF- $\mathrm{kB} 1$ was amplified to construct the NF-kappaB expression plasmid according to the human NF-kB neclotides sequences (NM_001165412.1) in GenBank. The CDS region containing adjacent three consecutive exons was amplified using pGL-NFKBFor and pGL-NFKBRev (Table 1), subcloned into pGL3-AA and pGL3-GG, named as pGL3-AA-NFKB and pGL3GG-NFKB respectively, while the random DNA fragments and above PCR products was subcloned into the vector pGL3-basic to construct recombinant plasmid pGL3-mock. The recombinant plasmids pGL3-AA and pGL3-GG were constructed for luciferase assay, while the expression plasmids pGL3-AA-NFKB and pGL3GG-NFKB were constructed for cell biological experiment. Non-gastric cell lines such as 293 T cells and Hela cells, gastric cancer cell lines such as MKN45 cells, HGC27 cells and SGC7901, were transfected with pGL3-AA and pGL3-GG using Lipofectamine 2000 (Invitrogen) respectively to verify the transcriptional activity of NFKB1 promoter. The expression plasmids were also transfected into SGC7901 cells, designated as 7901-pGL3-mock, 7901-pGL3-AA, and 7901-pGL3GG. The PCR reactions were carried out at $94^{\circ} \mathrm{C}$ for 2 min, then a 3-step cycle procedure was used (denaturation at $94^{\circ} \mathrm{C}$ for $30 \mathrm{~s}$, annealing at $57.3^{\circ} \mathrm{C}$ for $40 \mathrm{~s}$, and elongation at $70^{\circ} \mathrm{C}$ for $3.5 \mathrm{~min}$ ) for 39 cycles, with a final extension at $72^{\circ} \mathrm{C}$ for $10 \mathrm{~min}$.

\section{Transfection and luciferase assay}

The luciferase assay is one of the most convenient reporter assays to explore the regulation of gene expression in mammalian cell culture. The pGL3-basic vector only has the luciferase gene and lacks regulatory regions, such as promoter sequences. This vector is useful in the study of functional promoter elements to regulate gene expression. Renilla luciferase pRL-SV40 vector was used to normalize and reduce differences in transfection efficiencies and subsequent variations in these experiments.

For our luciferase assays, approximately $7 \times 10^{4}$ of SGC7901 cells were cultured in a 24-well plate in antibioticfree media. After attachment, cells were co-transfected with recombinant plasmids and pRL-SV40 vector by using Lipofectamine 2000 (Invitrogen, Carlsbad, CA). Other cell lines, such as 293 T cells, Hela cells, MKN45 cells and HGC27 cells, were transfected with these plasmids by the same method. LPS $(100 \mathrm{ng} / \mathrm{mL})$ was added into wells of stimulation group $24 \mathrm{~h}$ later. After $48 \mathrm{~h}$ incubation with cell culture media, then cells were lysed in passive lysis buffer (Promega, Wisconsin, USA). Firefly and Renilla luciferase signals were measured by the Dual-Luciferase ${ }^{\oplus}$ Reporter Assay System (Promega, Wisconsin, USA) in Synergy H4 Hybrid Microplate Reader (BioTek, Winooski, USA). Relative luciferase activity (Luc) calculated by the ratio of Firefly and Renilla luciferase signals was used to monitor the efficiency of transfection. 


\section{Chromatin immunoprecipitation}

Five million SGC-7901 cells were cross-linked with 1\% formaldehyde at room temperature for $10 \mathrm{~min}$. Chromatin extracts were obtained by cell lysis buffer. Sonication was performed 14 times for $4.5 \mathrm{~s}$ each at Power 25\% (Thermo $^{\text {ma }}$, Ultrasonic Cell Disruptor, Model XL) resulting in DNA fragments between 150 and $1000 \mathrm{bp}$ in size. Supernatants were collected and submitted to immunoprecipitation with $5 \mu \mathrm{g}$ of rabbit anti-C/EBP $\beta$ polyclonal antibody (sc-150X, Santa Cruz Biotechnology) and $20 \mu \mathrm{l}$ of magnetic protein A/G beads (Magna $\mathrm{ChIP}^{\mathrm{mix}} \mathrm{A} / \mathrm{G}$, Millipore, USA) overnight at $4^{\circ} \mathrm{C}$. In parallel, supernatants were incubated with normal rabbit IgG antibody as negative controls. Protein A/G magnetic beads were washed and pelleted by magnetic separator, and heated in ChIP Elution Buffer with Proteinase $\mathrm{K}$ at $65^{\circ} \mathrm{C}$ for 2 hours to reverse the cross-links of protein/DNA complexes. DNA fragments were purified on offered Spin columns. Finally, $4 \mu \mathrm{l}$ from a $30 \mu \mathrm{l}$ extraction were PCR amplified for NFKB1 promoter genes using the primers pGL-promoterFor1 and pGL-promoterRev (Table 1).

\section{Western blot analysis}

The rabbit anti-p50, anti-GAPDH antibody and the secondary antibody were purchased from Abcam (Cambridge, MA, USA). The C/EBP $\beta$ polyclonal antibody was purchased from Santa Cruz Biotechnology (Santa Cruz Biotechnology, CA, USA). Cultured cells were washed with phosphate-buffered saline and lysed on ice for 30 min with $500 \mu \mathrm{L}$ lysis buffer (Beyotime, China). The cell lysate was centrifuged at $4^{\circ} \mathrm{C}$ at $10,000 \times \mathrm{g}$ for $15 \mathrm{~min}$. The supernatant nuclear protein was used for Western blot. Twenty micrograms of cell extracts was loaded into $12 \%$ sodium dodecyl sulfate-polyacrylamide gel electrophoresis and subjected to Western blot. GAPDH was used as the internal control. Enhanced chemiluminescence detection was performed according to the manufacturer's instructions using X-photo film (Alpha Innotech, San Leandro, CA) and chemiluminescent substrate (Thermo Scientific, Rockford, IL).

\section{Cell proliferation and invasion assay}

For the cell proliferation assay, 7901-pGL3-mock, 7901pGL3-AA and 7901-pGL3-GG cells were grown at a density of $7 \times 10^{4}$ cells $/ \mathrm{mL}$ in 24 -well plates with regular medium changes. The cell number was counted every 24 hours for 6 days as follows: cells were detached by brief exposure to $0.025 \%$ trypsin containing $2 \mathrm{mM}$ EDTA in PBS, washed in culture medium without FBS, and then resuspended in the same medium for manual cell counting. For the invasion assays, matrigel was thawed at $4^{\circ} \mathrm{C}$ overnight, diluted in cold serum-free culture medium, plated onto 24-well plates preloaded with Transwell $^{\mathrm{Tm}}$ culture inserts $(12 \mathrm{~mm}$ diameter, $8 \mu \mathrm{m}$ pore size; Costar, Cambridge, MA, USA) and incubated for $5 \mathrm{~h}$ at $37^{\circ} \mathrm{C}$ for gelling. The cells were then plated onto the Transwell ${ }^{\mathrm{Tx}}$ inserts $(30,000$ cells/well) and cultured at $37^{\circ} \mathrm{C}$ in $5 \% \mathrm{CO}_{2}$. After $16 \mathrm{~h}$, the cells on the upper side of the well were removed and fixed prior to staining with hematoxylin and eosin. Cells migrating to the underside were counted under a microscope. All experiments were repeated at least three times.

\section{Apoptosis assay}

SGC-7901 cells were transfected with pGL3-AA-NFKB and pGL3-GG-NFKB respectively. At $48 \mathrm{~h}$ after transfection, cells were collected and resuspended in binding buffer containing Annexin V-PE and PI (BD Pharmingen, La Jolla, CA). Cell-associated fluorescence was analyzed with a FACS can instrument and associated Winlist 5 software.

\section{Statistical analysis}

For immunohistochemistry PI of NF-kB1 expression, data were analyzed by Kruskal-Wallis non-parametric tests. The difference in the levels of luciferase reporter gene expression between different groups was determined by Student's $t$ test and One-way ANOVA analysis (SPSS version 13.0; SPSS Inc., Chicago). Differences between variants were considered significant at $P<0.05$.

\section{Results}

\section{Expression of NF-KB1 in gastric cancer tissues}

In previous study, we conducted a large-scale casecontrol study on Chinese Han population to investigate the association of rs4648068 polymorphism with gastric cancer or clinic-pathologic variables of gastric cancer patients. To further verify its expression profile, 20 tissues from gastric cancer patients were analyzed by immunohistochemical staining. The corresponding genomic DNA of these patients was also performed genotyping analysis. Our data showed that the NF- $\mathrm{kB} 1$ protein $\mathrm{p} 50$ was located in both the cytoplasm and nuclei of gastric cancer tissues. Diffuse staining for p50 was observed in the tissues of GG genotype patients, compared with the GA group and the AA group (Figure 1). The immunohistochemistry PI of NF- $\mathrm{kB} 1$ expression for GG group was significantly higher than those of GA group and AA group, analyzed by Kruskal-Wallis non-parametric test $(P<0.01)$.

\section{The construction and identification of recombinant plasmid}

The promoter region containing NFKB1 polymorphisms rs4648068 (A > G) was subcloned into the vector pGL3basic successfully. The recombinant plasmids were named as pGL3-AA and pGL3-GG. In addition, pGL3-GG/TT containing SNP rs4648065 $(\mathrm{C}>\mathrm{T})$ was established using 

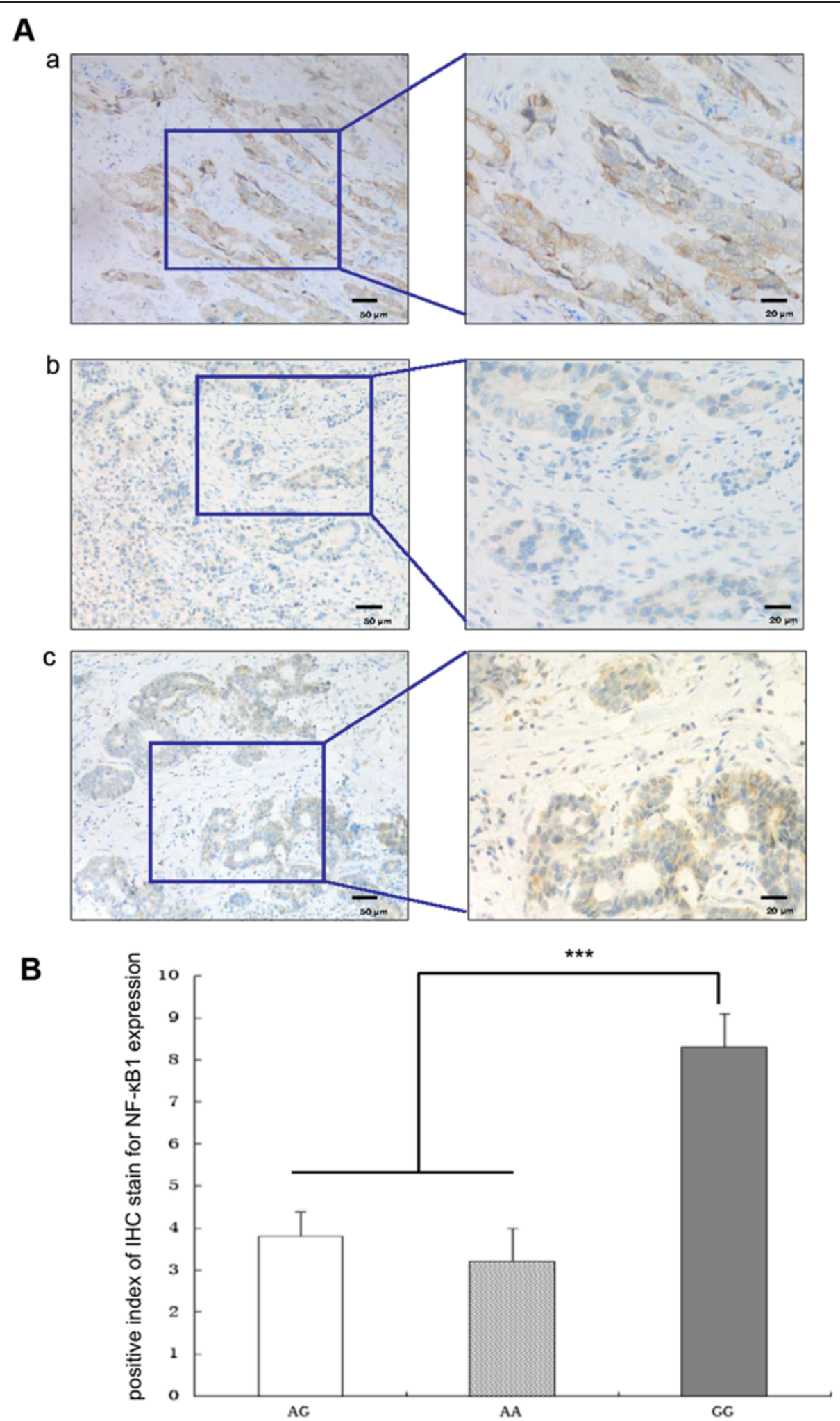

Figure 1 (See legend on next page.) 
(See figure on previous page.)

Figure 1 Expression of NF-KB1 in gastric cancer tissues. A. The staining results were shown. NF-KB1 (brown) is mainly expressed in cytoplasm of gastric adenocarcinoma tissue. (a) The patients' genotype was GG. Dark brown NF-kB1 cytoplasm staining was observed. (b) The patients' genotype was AA. NF-KB1 immunohistochemical staining of AA group exhibited faint. (c) The patients' genotype was GA. NF-KB1 immunohistochemical staining was also faint. Left panels magnification, $\times 200$; Right panels magnification, $\times 400$. B. Differences in NF-kappaB1 expression between different groups were invcestigated using Kruskal-Wallis non-parametric test. The immunohistochemistry PI of NF-kB1 expression for GG group was significantly higher than those of GA group and AA group $(P<0.01)$. ${ }^{* *} P<0.01,{ }^{* *} P<0.05$.

the same method to investigate the co-effect on rs4648068. Furthermore, adjacent three consecutive exons for NF-kB1 was amplified and subcloned into pGL3-AA and pGL3-GG respectively, named as pGL3AA-NFKB and pGL3-GG-NFKB. Nucleotide sequence further confirmed that the sequence of recombinant plasmid was correct without base mutation and deletion, and the sequence inserted was corrected by comparing with GenBank as is shown in Figure 2. Subsequently, we confirmed that the recombinant luciferase could be expressed in the transduced cells.

\section{Gene expression activity was associated with NFKB1 polymorphisms}

To examine the functional activity of NFKB1 promoter variations $A>G$ (rs4648068), as well as the synergistic effect by $\mathrm{C}>\mathrm{T}$ (rs4648065), which was described in our previous study, different recombinant plasmids containing

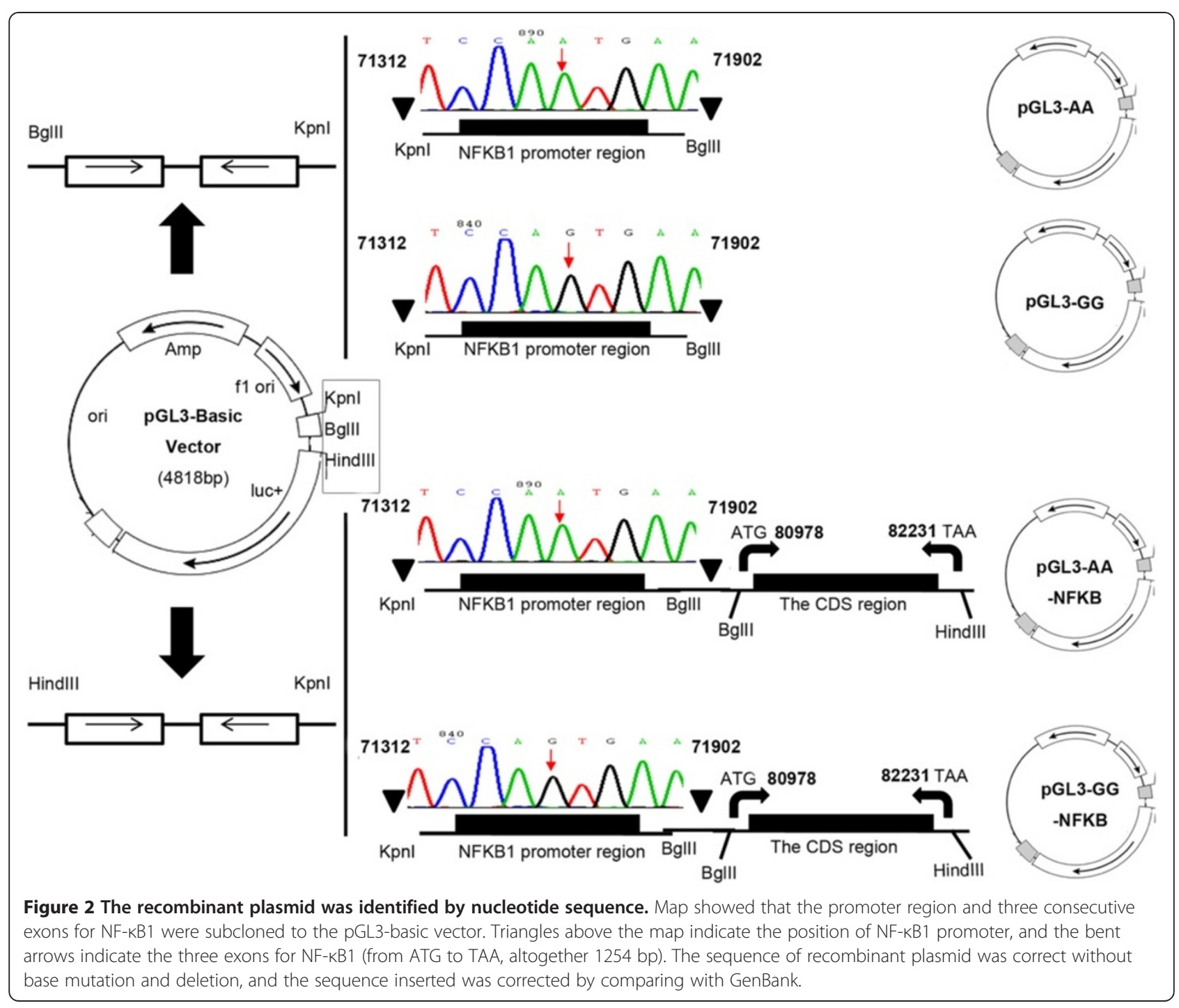


homozygote site were transiently transduced for transcriptional activity evaluation, 48-hours after transfection, renilla and firefly luciferase activities were measured. For non-gastric cell lines, luciferase activity for GG homozygote $(4.53 \pm 0.81)$ were higher than that of AA homozygote $(1.94 \pm 0.37)$ in $293 \mathrm{~T}$ cells $(P=0.041)$. In Hela cells, the luciferase activity for GG homozygote $(7.09 \pm 0.91)$ were also greater, compared with that of AA homozygote $(1.97 \pm 0.38, P=0.002)$. For gastric cell lines, the luciferase expression ratios (7.12 \pm 0.68 for MKN45 cells, $5.80 \pm 0.42$ for HGC27 cells, and $8.80 \pm 0.64$ for 7901 cells) in GG homozygote were observed higher than AA homozygote (3.56 \pm 0.67 for MKN45 cells, $3.09 \pm 0.43$ for HGC27 cells, and $3.36 \pm 0.30$ for 7901 cells; $P=0.022, P=0.04$ and $P=$ 0.004 , respectively) with significant difference (Figure $3 \mathrm{~A}$ ). Moreover, two homozygote GG/TT panel for gastric cell lines $(11.23 \pm 0.38$ for HGC27 cells, and 11.52 \pm 0.15 for 7901 cells) showed stronger luciferase activity than that of homozygote GG panel $(5.80 \pm 0.42$ for HGC27 cells, and $8.80 \pm 0.64$ for 7901 cells; $P=0.001, P=0.038$ respectively) (Figure $3 \mathrm{~B}$ ). The result showed that the luciferase activity of homozygote group (pGL3-GG) was greater than control group (pGL3-AA) $(P<0.05)$ (Figure 3A). Moreover, the luciferase activity of two homozygote site group
(pGL3-GG/TT) was the strongest with significant difference in Figure 3B $(P<0.05)$. The difference was determined by One-way ANOVA analysis (SPSS version 13.0; SPSS Inc., Chicago). It indicated that SNP rs4648068 significantly influenced luciferase gene expression in various cell lines. In addition, we found that the effect of NFKB1 polymorphism rs4648068 was enhanced by polymorphism rs4648065.

\section{The effect of NFKB1 rs4648068 influenced by LPS stimulation}

The bacterial product LPS plays a role in the NF- $\mathrm{kB}$ signaling pathway. Thus, we investigated the effect of NFKB1 rs4648068 on LPS-stimulated luciferase activity. Both of recombinant plasmid pGL3-AA and pGL3-GG containing the promoter region were transduced to SGC7901 cells. The difference between luciferase activities of GG and AA reporters was estimated under the stimulation of LPS (Table 2). In the control group without LPS stimulation, the relative luciferase activity of pGL3-GG was greater than that of pGL3-AA, and the most effective concentration of recombinant plasmid was $100 \mathrm{ng} / \mathrm{mL}$. Under the stimulation of LPS, the increased range of relative luciferase activity was elevated greatly. To compare the luciferase

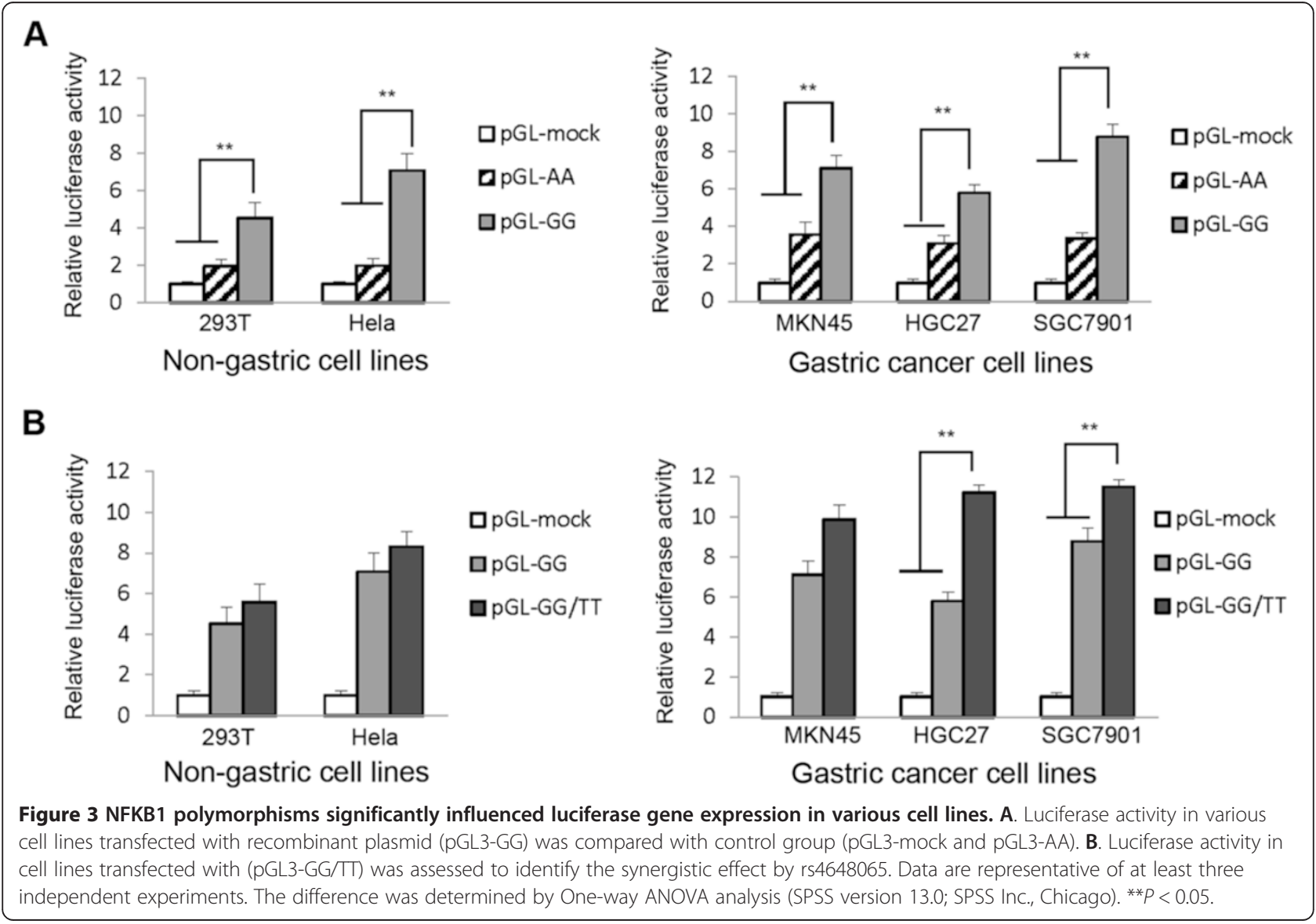


Table 2 The increased luciferase activity in LPS-stimulated SGC-7901 cells and control cells

\begin{tabular}{lllll}
\hline \multicolumn{4}{l}{ The increased luciferase activity ${ }^{\boldsymbol{\Lambda}}$ of recombinant plasmid } \\
\hline Group & $25 \mathrm{ng} / \mathrm{mL}$ & $50 \mathrm{ng} / \mathrm{mL}$ & $100 \mathrm{ng} / \mathrm{mL}$ & $150 \mathrm{ng} / \mathrm{mL}$ \\
Control & $0.34 \pm 0.03$ & $0.91 \pm 0.23$ & $1.77 \pm 0.53^{* *}$ & $1.19 \pm 0.36$ \\
LPS & $2.86 \pm 0.17^{\#}$ & $4.54 \pm 0.19^{\#}$ & $5.32 \pm 0.27^{\#}$ & $5.74 \pm 0.44^{\#}$
\end{tabular}

Control group, unstimulated transduced cells; ${ }^{{ }}$, increased Luc $=$Luc (GG)-Luc (AA); ${ }^{\prime}, P<0.01$, compared with control group respectively (Student's $t$ test); **, $P<0.05$, compared with other concentration levels $(25 \mathrm{ng} / \mathrm{mL}, 50 \mathrm{ng} / \mathrm{mL}$ and $150 \mathrm{ng} / \mathrm{mL}$ ) (One-way ANOVA.)

activity, we found that the increased range in LPSstimulated group was more obvious than the control group with significant difference, analyzed by Student's $t$ test (Table 2). It suggested that the SNP rs4648068 can enhance the transcriptional activity of NFKB1, especially in LPS response.

Effects of polymorphisms on protein expression

$\mathrm{C} / \mathrm{EBP} \beta$ (CAAT/enhancer binding proteins) is a transcription factor that can bind as a homodimer to certain DNA regulatory regions. To further define the role of rs4648068, chromatin immunoprecipitation assay (ChIP) was used to investigate the interaction between $C / E B P \beta$ and NFKB1 promoter in the SGC-7901 cell. The recombinant plasmid pGL3-AA-NFKB and pGL3-GG-NFKB, which contain the promoter region of NFKB1 and adjacent three consecutive exons, were transduced to the SGC-7901 cells, recognized as 7901-pGL3-AA cells and 7901-pGL3-GG cells. We found, as expected, that C/EBP $\beta$ bound to the NFKB1 promoter containing the SNP site (Figure 4A). Meanwhile, western blotting showed a higher level of p50 and C/EBP $\beta$ expression in 7901-pGL3-GG cells, compared with those of 7901-pGL3-mock cells and 7901- pGL3-AA cells (Figure 4B). It seems that C/EBP $\beta$ binds better to the GG version of NFKB1 promoter and enhances the transcription of NFKB1. On the other hand, NF- $\mathrm{kB} 1 \mathrm{p} 50$ could bind $\mathrm{C} / \mathrm{EBP} \beta$ and reciprocally induce partner's expression, forming a transcriptional positive feedback loop, contributing to the upregulated p50 and C/ $\mathrm{EBP} \beta$ expression (Figure $4 \mathrm{C}$ ). Since NF-kB1, as well as $\mathrm{C} /$ $\mathrm{EBP} \beta$, plays a role in the cell proliferation, differentiation, signaling pathway and the occurrence of tumors. The SNP site rs4648068 might have effect on cell proliferation and

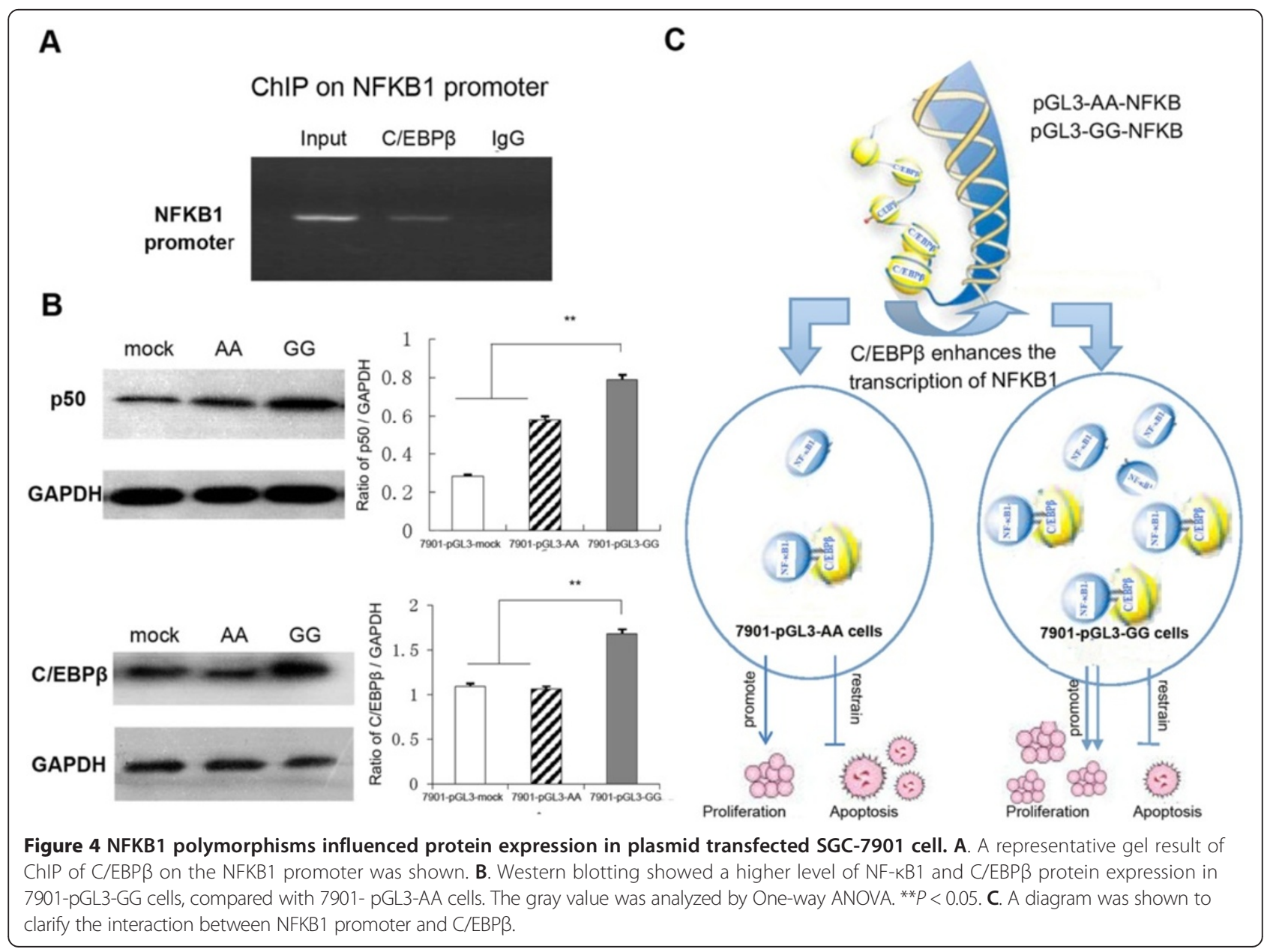


A

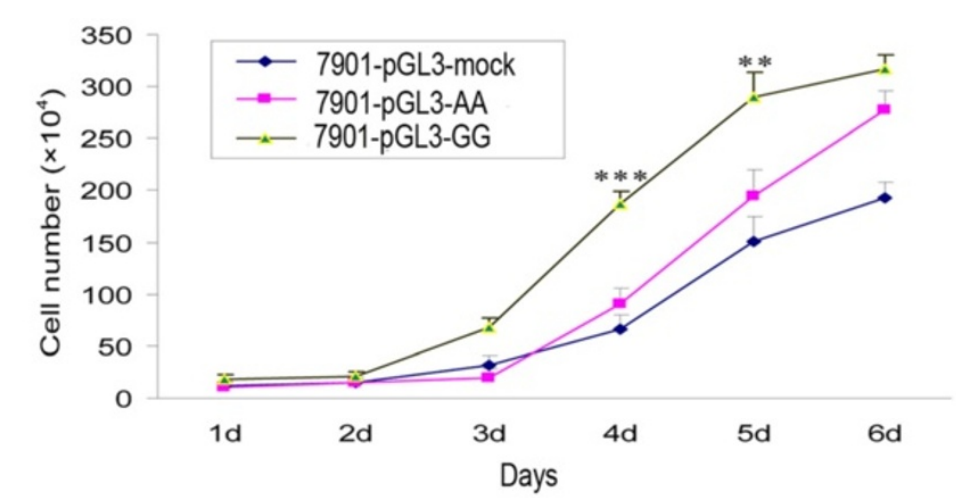

B
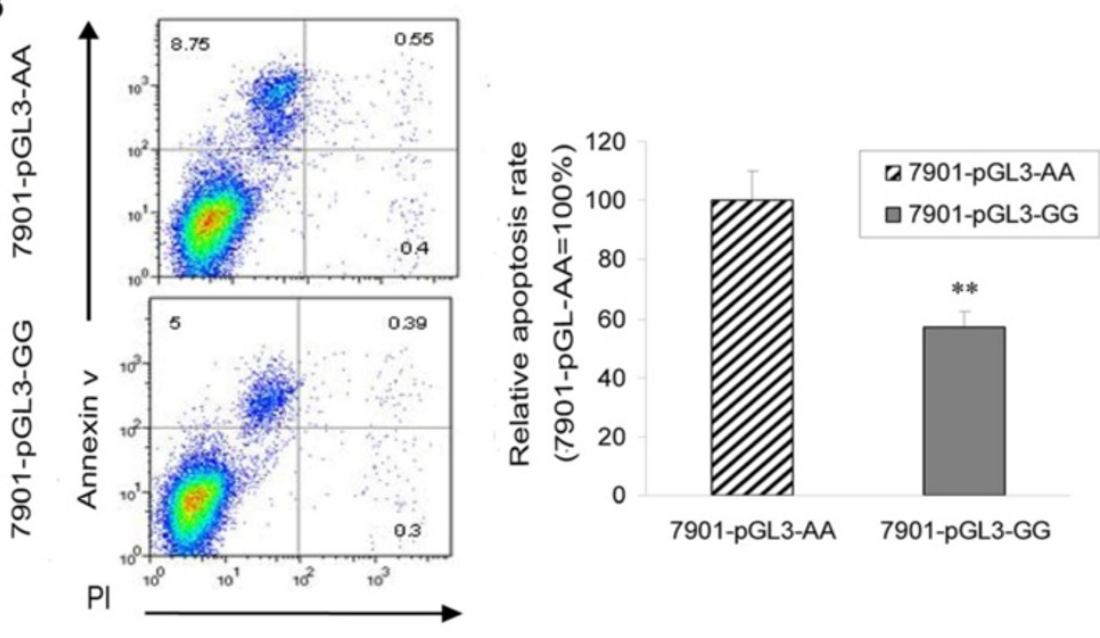

C
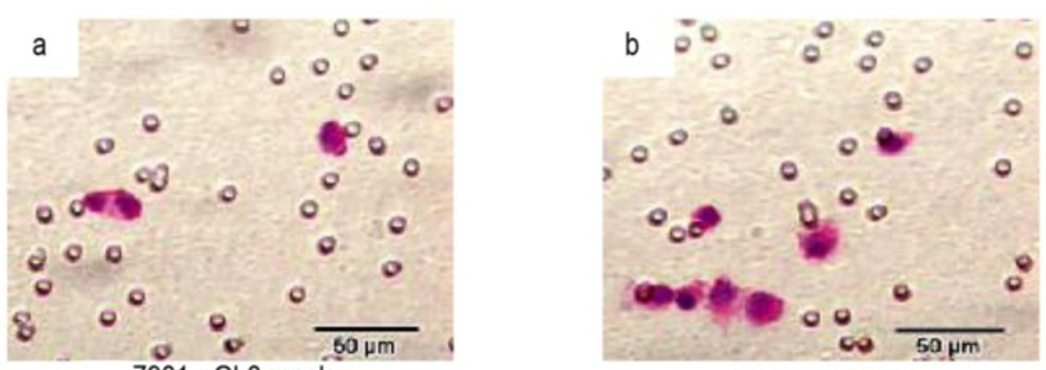

7901-pGL3-mock
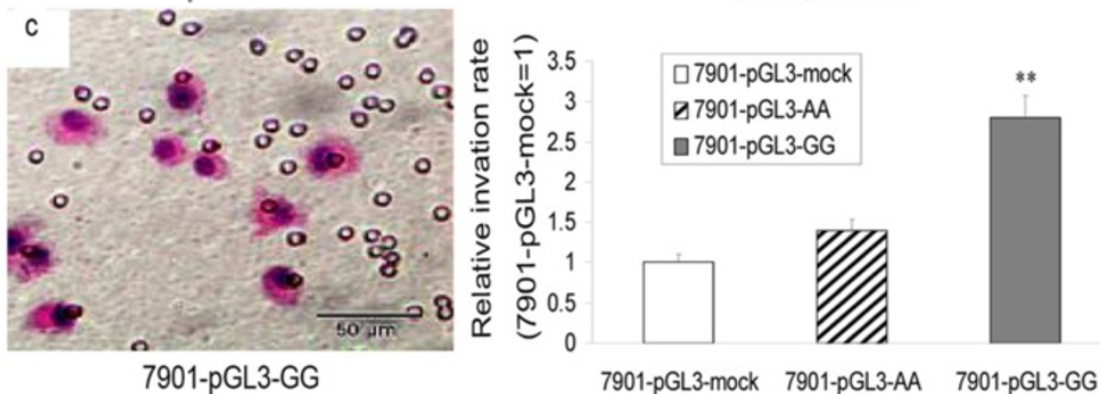

Figure 5 (See legend on next page.) 
(See figure on previous page.)

Figure 5 The SNP rs4648068 influenced cell proliferation, apoptosis percentage and invasive ability. A. Cell proliferation was significantly elevated in 7901-pGL3-GG cells compared with 7901-pGL3-AA cells and 7901-pGL3-mock cells. B. In each box, the lower left corner included viable cells, which were both Annexin V-FITC and PI negative. In the upper left corner, cells are in early apoptosis with Annexin V-FITC positive and PI negative. While the upper right corner included necrotic or late apoptotic cells are both FITC Annexin V and PI positive. In 7901-pGL3-GG cells, the percentage of apoptosis cells decreased significantly, compared with 7901-pGL3-AA. C. The invasion ability was increased in 7901-pGL3-GG cells (c) than control cells (a, b). 200x. a, 7901-pGL3-AA cells; b, 7901-pGL3-mock cells; c, 7901-pGL3-GG cells. Data were assessed by One-way ANOVA analysis. ${ }^{* *} P<0.01 ;{ }^{* *} P<0.05$.

motility by regulating NF- $\mathrm{kB} 1$ and $\mathrm{C} / \mathrm{EBP} \beta$. However, the mechanism for regulating $\mathrm{C} / \mathrm{EBP} \beta$ expression remains unclear, and will be performed in our future work.

\section{Proliferation and invasion ability of transfected SGC-7901 cells}

To further analyze the cell biological function of SNP rs4648068, we conducted proliferation and invasion assay in transfected SGC-7901 cells. Proliferation was assessed by cell counting under an optical microscope for six days. The proliferative rate of 7901-pGL3-GG cells was observed faster than 7901-pGL3-AA cells and 7901pGL3-mock cells (Figure 5A). For the invasion assay, 7901-pGL3-GG cells showed a higher ability to migrate, compared with 7901-pGL3-AA cells and 7901-pGL3mock cells (Figure $5 \mathrm{C}$ ). It illustrated that the proliferation and invasiveness of SGC-7901 was enhanced by transfection of the recombinant plasmid containing SNP site. To guarantee the effective transduction, all the experiments were completed within six days after the transfection.

\section{Apoptosis assay}

SGC-7901 cells were transfected with pGL3-AA-NFKB and pGL3-GG-NFKB respectively. At $48 \mathrm{~h}$ after transfection, cells were collected and resuspended in binding buffer containing Annexin V-FITC and PI, and then processed for flow cytometry analysis. In 7901-pGL3-GG cells, the percentage of apoptosis cells decreased significantly, compared with 7901-pGL3-AA cells (Figure 5B). The result demonstrated that in certain situations NF- $\mathrm{kB} 1$ acts as an anti-apoptotic protein.

\section{Discussion}

Our previous study indicated that NFKB1 polymorphism at intron region (rs4648068) was associated with increased risk of gastric cancer in Chinese Han population. The present study focused on the investigation of NFKB1 transcriptional activity and biological function influenced by rs4648068 (A > G) polymorphism.

It was reported that NF- $\mathrm{kB}$ is constitutively activated in gastric carcinoma tissue [12]. Kwon $\mathrm{HC}$ et al. [13] demonstrated that the expression of NF- $\mathrm{kB}$ is increased in human gastric cancer tissue. The nuclear translocation of Rel A (used as a marker of NF- $\mathrm{kB}$ activation) was significantly greater in gastric cancer cells than in adjacent normal epithelial cells [14]. Yamanaka et al. [15] reported that gastric cancer patients with high levels of NF- $\mathrm{kB}$ expression had a lesser overall survival than patients with low levels of NF-кB. The evidence presented above suggested that NF- $k B$ play an important role in the genesis and progression of gastric cancer. Moreover, immunohistochemical staining experiments were conducted to determine in-depth relationship between NF- $\mathrm{kB} 1$ expression and SNP site rs4648068. NF-kB1 p50 was found highly expressed in the homozygote GG group compared with the control group. It indicated that the functional site has effects on NFKB1 transcriptional activity and regulates its expression.

The luciferase assay is one of the techniques to study the regulation of gene expression in mammalian cell culture $[16,17]$. The transcriptional activity could be assessed by calculating the relative luciferase activity of plasmid transfected cells [18]. For luciferase assays, our results showed that the transcriptional activity of NFKB1 was influenced by SNP rs4648068 at gene expression levels. Moreover, the effect on rs4648068 by rs4648065 was also observed at gene transcriptional activity. Our data suggested that rs4648068 GG may upregulate the expression of NFKB1, especially under the influence of rs4648065.

According to our data, the SNP rs4648068 can enhance the transcriptional activity of NFKB1, especially in LPS response. This indicated that the effect of NFKB1 rs4648068 could be influenced by LPS stimulation. Under the LPS stimulation, subsequent reaction occurs through toll-like receptor (TLR)-4-induced signal transduction, which then targets down-stream NF-кB pathway [19]. The activation of NF- $\mathrm{kB}$ was affected by LPS stimulation [20]. Similarly, the effect of polymorphism rs4648068 on NFkB1 expression could be strengthened by LPS stimulation.

Liu et al. reported that various SNPs of cancer related genes are associated with a faster progression of cancers [21]. Polymorphisms in the promoter regions of genes might potentially modulate the gene expression which in turn influence the cell biological activity [18,22]. CHIP assay provided evidence indicating that $\mathrm{C} / \mathrm{EBP} \beta$ can bind to the NFKB1 promoter containing the SNP site [23], We considered that, $\mathrm{C} / \mathrm{EBP} \beta$ bound better to the $\mathrm{GG}$ version of NFKB1 promoter and enhanced the transcription of NFKB1, giving rise to the upregulated p50 expression. In addition, NF- $\mathrm{KB} 1 \mathrm{p} 50$ could bind $\mathrm{C} / \mathrm{EBP} \beta$ and reciprocally 
induce each other's expression [24], forming a transcriptional positive feedback loop. In fact, C/EBP $\beta$ was also confirmed upregulated in the homozygote GG group, accompanied with a higher level of NF-kB1. The mechanism for regulating $C / E B P \beta$ expression remains unclear, and will be performed in our future work. C/EBP $\beta$ :p50 interaction could induce target genes to influence the cell biological activity [25]. Consequently, the SNP site rs4648068 might influence the cell biological activity by regulating NF- $\mathrm{kB} 1$ and $\mathrm{C} / \mathrm{EBP} \beta$ expression.

The NFKB1 polymorphism (rs4648068) was found associated with the cell proliferation and motility in gastric cancer in this study. For the proliferation and invasion assay, the result showed difference in biological activity between transfected cells and control cells. 7901-pGL3GG cells showed increased ability of growth and invasion, compared with 7901-pGL3-AA cells. For the apoptosis assay, the percentage of apoptosis cells for 7901-pGL3-GG cells decreased significantly, compared with 7901-pGL3-AA cells. The finding suggested that SNP rs4648068 may play a role in regulating gastric cancer cell biological activity.

In this study, we have demonstrated that the NFKB1 polymorphism (rs4648068) is associated with the cell proliferation and motility in gastric cancer. The underlying cellular and molecular mechanisms involve related signaling pathway, such as NF- $\mathrm{kB}$ pathway and MAPK pathway. MAPK pathway, as well as NF- $\mathrm{KB}$ pathway, is considered the major signaling pathway induced by mediator such as LPS. In the MAPK family, p38 MAPK, c-JNK and ERKs are the most important components. The role of NFKB1 polymorphism (rs4648068) in the regulation of the gene described above should be further studied.

\section{Conclusions}

In summary, the data presented confirmed that the transcriptional activity of NFKB1 was associated with SNP rs4648068. In addition, the functional activity of SNP site was verified by cell biology experiment.

\section{Competing interests}

The authors declare that they have no competing interests.

\section{Authors' contributions}

RQL provided conception and design. YC analyzed the data and participated in drafting the manuscript. XG participated in clinical data and information collection. RX and HZ performed apoptosis assay. JJF collected all samples. LG conceived and supervised the project and reviewed the manuscript. All authors have read and approved the final manuscript.

\section{Acknowledgements}

This study was financially supported by the grants from Science and Technology Commission of Shanghai Municipality (124119a0202 and 114119a0400), and the foundation of National Basic Research Program of China (2010CB933902). The project was also supported by Open Fund of Key Laboratory of Carcinogenesis and Cancer Invasion, Fudan University, Ministry of Education (KLCC12014-2).
Received: 27 September 2014 Accepted: 29 January 2015

Published online: 14 February 2015

\section{References}

1. Chen CD, Sawyers CL. NF-kappa B activates prostate-specific antigen expression and is upregulated in androgen-independent prostate cancer. Mol Cell Biol. 2002:22(8):2862-70.

2. Karin M, Cao Y, Greten FR, Li ZW. NF-kappaB in cancer: from innocent bystander to major culprit. Nat Rev Cancer. 2002;2(4):301-10.

3. Siebenlist U, Franzoso G, Brown K. Structure, regulation and function of NF-kappa B. Ann Rev Cell Biol. 1994;10:405-55.

4. Baldwin Jr AS. The NF-kappa B and I kappa B proteins: new discoveries and insights. Ann Rev Immunol. 1996;14:649-83.

5. Wang W, Abbruzzese JL, Evans DB, Chiao PJ. Overexpression of urokinasetype plasminogen activator in pancreatic adenocarcinoma is regulated by constitutively activated RelA. Oncogene. 1999;18(32):4554-63.

6. Tai DI, Tsai SL, Chang YH, Huang SN, Chen TC, Chang KS. Constitutive activation of nuclear factor kappaB in hepatocellular carcinoma. Cancer. 2000;89(11):2274-81.

7. Biswas DK, Dai SC, Cruz A, Weiser B, Graner E, Pardee AB. The nuclear factor kappa B (NF-kappa B): a potential therapeutic target for estrogen receptor negative breast cancers. Proc Natl Acad Sci U S A. 2001;98(18):10386-91.

8. Pan X, Li Y, Feng J, Wang X, Hao B, Shi R, et al. A functional polymorphism T309G in MDM2 gene promoter, intensified by Helicobacter pylori lipopolysaccharide, is associated with both an increased susceptibility and poor prognosis of gastric carcinoma in Chinese patients. BMC Cancer. 2013;13:126

9. Xu M, Tao G, Kang M, Gao Y, Zhu H, Gong W, et al. A polymorphism (rs2295080) in mTOR promoter region and its association with gastric cancer in a Chinese population. PLoS One. 2013;8(3):e60080.

10. Lu R, Gao X, Chen Y, Ni J, Yu Y, Li S, et al. Association of an NFKB1 intron SNP (rs4648068) with gastric cancer patients in the Han Chinese population. BMC Gastroenterol. 2012;12:87.

11. Lu R, Wu C, Guo L, Liu Y, Mo W, Wang H, et al. The role of brevican in glioma: promoting tumor cell motility in vitro and in vivo. BMC Cancer. 2012;12:607.

12. Long YM, Ye S, Rong J, Xie WR. Nuclear factor kappa B: a marker of chemotherapy for human stage IV gastric carcinoma. World J Gastroenterol. 2008;14(30):4739-44.

13. Kwon HC, Kim SH, Oh SY, Lee S, Lee JH, Jang JS, et al. Clinicopathologic significance of expression of nuclear factor-kappaB RelA and its target gene products in gastric cancer patients. World J Gastroenterol. 2012;18(34):4744-50.

14. Sasaki N, Morisaki T, Hashizume K, Yao T, Tsuneyoshi M, Noshiro H, et al. Nuclear factor-kappaB p65 (RelA) transcription factor is constitutively activated in human gastric carcinoma tissue. Clin Cancer Res. 2001;7(12):4136-42.

15. Yamanaka N, Sasaki N, Tasaki A, Nakashima H, Kubo M, Morisaki T, et al. Nuclear factor-kappaB p65 is a prognostic indicator in gastric carcinoma. Anticancer Res. 2004;24(2C):1071-5.

16. Zhao F, Chen X, Meng T, Hao B, Zhang Z, Zhang G. Genetic polymorphisms in the osteopontin promoter increases the risk of distance metastasis and death in Chinese patients with gastric cancer. BMC Cancer. 2012;12:477.

17. Bayerer B, Stamer U, Hoeft A, Stuber F. Genomic variations and transcriptional regulation of the human mu-opioid receptor gene. Eur J Pain. 2007;11(4):421-7.

18. Verma VK, Taneja V, Jaiswal A, Sharma S, Behera D, Sreenivas $V$, et al. Prevalence, distribution and functional significance of the $-237 \mathrm{C}$ to $\mathrm{T}$ polymorphism in the IL-12Rbeta2 promoter in Indian tuberculosis patients. PLOS One. 2012;7(4):e34355.

19. Pahl HL. Activators and target genes of Rel/NF-kappaB transcription factors. Oncogene. 1999;18(49):6853-66.

20. Kato T, Kitagawa S. Regulation of neutrophil functions by proinflammatory cytokines. Int J Hematol. 2006;84(3):205-9.

21. Liu JL, Liang Y, Wang ZN, Zhou X, Xing LL. Cyclooxygenase-2 polymorphisms and susceptibility to gastric carcinoma: a meta-analysis. World J Gastroenterol. 2010;16(43):5510-7.

22. Wu DM, Zhu HX, Zhao QH, Zhang ZZ, Wang SZ, Wang ML, et al. Genetic variations in the SMAD4 gene and gastric cancer susceptibility. World J Gastroenterol. 2010;16(44):5635-41.

23. Paz-Priel I, Houng S, Dooher J, Friedman AD. C/EBPalpha and C/EBPalpha oncoproteins regulate $\mathrm{nfkb1}$ and displace histone deacetylases from NF-kappaB p50 homodimers to induce NF-kappaB target genes. Blood. 2011;117(15):4085-94. 
24. Schmid RM, Perkins ND, Duckett CS, Andrews PC, Nabel GJ. Cloning of an NF-kappa B subunit which stimulates HIV transcription in synergy with p65. Nature. 1991;352(6337):733-6.

25. Dooher JE, Paz-Priel I, Houng S, Baldwin Jr AS, Friedman AD. C/EBPalpha, C/EBPalpha oncoproteins, or C/EBPbeta preferentially bind NF-kappaB p50 compared with p65, focusing therapeutic targeting on the C/EBP:p50 interaction. Mol Cancer Res. 2011;9(10):1395-405.

Submit your next manuscript to BioMed Central and take full advantage of:

- Convenient online submission

- Thorough peer review

- No space constraints or color figure charges

- Immediate publication on acceptance

- Inclusion in PubMed, CAS, Scopus and Google Scholar

- Research which is freely available for redistribution 